\title{
Residual feed intake, digestibility of nutrients and efficiency of water utilizations in Murrah buffalo heifers
}

\begin{abstract}
A metabolism trial was conducted for $7 \mathrm{~d}$ to determine residual feed intake (RFI=measure of the difference between actual feed intake and expected feed requirement), dry matter intake (DMI), digestibility and metabolism of nutrients at the end of a 57 days (d) of a feeding trial with 18 Murrah buffalo heifers $(279 \mathrm{~kg} \pm 16$; and $684 \pm 131 \mathrm{~d}$ of age). Preliminary selection of heifers as efficient and less efficient was done by regressing actual DMI on predicted DMI $(\mathrm{g} / \mathrm{head} / \mathrm{d})$ using the model DMI $(\mathrm{g} / \mathrm{kg} \mathrm{BW})=\beta_{0}+\beta$ predicted DMI $(\mathrm{g} / \mathrm{kg} \mathrm{BW})$ and RFI categories were sorted out by regressing mean DMI for the 57 days feeding period on BWG and mid-test MBW using the model $\mathrm{Yi}=\beta 0+\beta 1 \mathrm{BWG}(\mathrm{g} / \mathrm{d})+\beta 2$ mid-test $\mathrm{MBW}(\mathrm{kg})+\mathrm{ei}$; where $\mathrm{Yi}=\mathrm{DMI}$, $\beta 0=$ regression intercept, $\beta 1$ and $\beta 2=$ regression coefficients on $B W G$ and mid-test MBW, respectively, and ei=uncontrolled error or RFI, heifers with +ve RFI values are less efficient and those with -ve RFI values efficient. Differences were not statistically significant. The actual dry matter (DM), crude protein $(\mathrm{CP})$, digestible organic matter (DOM) and total digestible nutrient (TDN) intakes of RFI-I heifers $(6.73 \pm 0.56 ; 0.99 \pm 0.008 ; 5.06 \pm 0.47 ;$ and $4.95 \pm 0.47 \mathrm{~kg} / \mathrm{head} / \mathrm{d}$, respectively) were not different from those of RFI-II $(6.51 \pm 0.50 ; 0.97 \pm 0.07 ; 5.11 \pm 0.42$; and $5.00 \pm 0.42 \mathrm{~kg}$ / head/d, respectively). RFI-II heifers digested DM, OM and NDF $(70.84 \pm 1.48$; $73.96 \pm 1.54$ and $66.33 \pm 2.08 \%$, respectively) better than those of RFI-I heifers $(68.74 \pm 1.66 ; 71.49 \pm 1.72 \%$ and $63.05 \pm 2.32 \%$, respectively) and thus RFI-II had higher $\mathrm{N}$ balance $(45 \pm 8 \mathrm{head} / \mathrm{d})$ than that of RFI-I heifers $(38 \pm 9 \mathrm{~g} / \mathrm{head} / \mathrm{d})$. Water loss per unit of water intake (WI) in feces of RFI-II $(69.70 \pm 8.40 \%)$ was lower than that of RFI-I heifers $(73.41 \pm 9.39 \%)$ and improved amount of water available for RFI-II for metabolism as a result of which water loss in urine proportionally increased in RFI-II $(32.65 \pm 2.04 \% \mathrm{WI})$ than in RFI-I heifers $(31.84 \pm 2.28 \% \mathrm{WI})$. Water loss per unit of DMI in feces $(157 \pm 18$ vs. $145 \pm 16 \%$ DMI $)$ and urine $(69 \pm 10$ vs. $76 \pm 9 \%$ DMI, for RFI-I vs. RFI-II, respectively) followed similar trend as that of water loss per unit of WI. Mainly because of small sample size differences in nutrient intakes between RFI-I and RFI-II heifers were not significant; however, RFI-II with similar feed intake had higher N-balance, digestibility of nutrients and level of water utilization and could be selected as being more feed efficient heifers.
\end{abstract}

Keywords: digestibility, murrah buffalo heifers, nutrient efficiency, nutrient intake, water efficiency
Volume 5 Issue 2 - 2017

\author{
Tegene Negesse,' Chander Datt, ${ }^{2}$ Shivlal S \\ Kundu ${ }^{2}$ \\ 'Hawassa University, Ethiopia \\ ${ }^{2}$ National Dairy Research Institute, India
}

Correspondence: Tegene Negesse, School of Animal and Range Sciences, Hawassa University, Hawassa, Ethiopia, Tel +25 916827 7II, Fax +25। 04622067 II, Email tegenengss38@gmail.com

Received: March 23, 2017| Published: April 21, 2017

\section{Introduction}

Reduced productivity of livestock in most parts of the world including India is mainly caused by scarcity of feed which demands improvement in feed efficiency. Feed is also the most expensive input for livestock production system, and approximately $65 \%$ of the total feed requirements being used to maintain the cowherd ${ }^{1}$ and 70 to $75 \%$ of the total dietary energy cost in beef production being used for maintenance. ${ }^{2,3}$ If much of the feed cost is used for maintenance, improving feed efficiency can have a big economic effect and can bring large improvement in profitability and environmental credentials. It has been found out that proportional amount of improvement in feed efficiency raises the economic impact. ${ }^{4}$ Gross efficiency (GE) as a ratio between feed inputs and production outputs is a useful measure for nutritional studies in uniform genotypes ${ }^{5}$ but not between genotypes. It favors genotypes with high growth rates where over $50 \%$ of the feed is used for maintenance. ${ }^{6}$ Maintenance requirement at maturity is not accounted for by GE.

An alternative measure of feed efficiency is residual feed intake
(RFI) or net feed efficiency ${ }^{7}$ that is defined as the difference between actual feed intake and its expected maintenance and growth feed requirements. Residual feed intake would be an improved measure of feed efficiency due to its independence from body weight and body weight gain. ${ }^{7}$ It was also demonstrated that there is adequate potential for selection against RFI to improve feed conversion ratio (FCR) and efficiency of maintenance energy expenditure. ${ }^{8}$ With the heritability of RFI varying between 0.29 and 0.46 , selection for low RFI has added advantages of improving FCR; calf-weight-per-cow feed intake; with no effect on average daily gain or mature size or efficiency of adult cattle and progeny. ${ }^{9}$ In this research work a metabolism trial was conducted to see if there is any association between RFI values and nutrient digestibility and balance in Murrah Buffalo heifers.

\section{Materials and methods}

\section{Description of the study area}

The study was conducted in National Dairy Research Institute (NDRI), Karnal, Haryana, India which is situated at an altitude of 
$250 \mathrm{~m}$. a. s. $1,24^{0} 42^{\prime}$ N latitude and $79^{\circ} 54^{\prime \prime}$ E longitude. The maximum and minimum annual temperatures are $45^{\circ} \mathrm{C}$ and $10^{\circ} \mathrm{C}$, respectively. Field work was done at the Livestock Research Center (cattle yard) and laboratory analyses in the Dairy Cattle Nutrition Division of NDRI between June and November 2013.

\section{Feeding and metabolism trial}

A feeding trial was conducted with eighteen Murrah buffalo heifers of $238 \pm 63 \mathrm{~kg}$ and $627 \pm 131$ days old that were selected from the Livestock Research Center of NDRI, Karnal, Haryana, India. The heifers were fed for 57days the animals were fed based on their body weight and assumed daily weight gain of $0.5 \mathrm{~kg} / \mathrm{head} / \mathrm{d}$ according to ${ }^{5}$ and it was then raised by $10 \%$ to make the feeding regime Ad libitum. Of the total DM required, $60 \%$ was from green feed and $40 \%$ from concentrate. Once the DM requirements of individual heifers from the green feed and concentrate were predicted (predicted DMI), the daily fresh offers were calculated based on the DM contents of the green fodder (measured daily) and concentrate. At the end of the $57 \mathrm{~d}$ feeding trial, heifers attained an average weight of $281 \pm 15 \mathrm{~kg}$ and were divided in to less efficient (RFI-I, $278 \pm 22 \mathrm{~kg}$ ) and efficient (RFIII, $284 \pm 20 \mathrm{~kg}$ ) RFI groups first by regressing actual DMI on predicted DMI and then by regressing mean DMI on BWG and mid-test MBW and moved to individual crates for metabolism trial.

The animals were fed Ad libitum, about 3\% of their body weight and assumed daily weight gain of $0.5 \mathrm{~kg} / \mathrm{head} / \mathrm{d}$; and at the refusal rate of $10 \% .^{5}$ Of the total DM required, $60 \%$ was from green feed and $40 \%$ from concentrate. Once the DM requirements of individual heifers from the green feed and concentrate were predicted (predicted DMI), the daily fresh offers were calculated based on the DM contents of the green fodder (measured daily) and concentrate. After three d of adaptation data on feed and water offered and refused, feces and urine voided were collected and measured for seven d. Heifers were weighed at the beginning and end of the metabolism trial using a weigh bridge. Measured amount of the green feed (sorghum/maize/ bajra=perle millet) and the concentrate (maize $33 \%$, groundnut cake $21 \%$, mustard cake $12 \%$, wheat bran $20 \%$, rice bran $11 \%$, mineral mixture $2 \%$ and common salt $1 \%$ ) were fed mixed together for each heifer in individual feed troughs between 9:00 and 10:00h. Measured amount of water was offered in individual buckets twice daily at about 10:00h and 16:00h and refused water measured immediately. Feed residues were collected in the morning at 6:00h.

Heifers were put in individual crates whose floors were regularly cleaned with tape water. Feces were hand-picked from the floor of the cages as soon as defecated and urine voided rolled over the floor into urine collection bottle with $5 \mathrm{ml}$ of $25 \% \mathrm{H}_{2} \mathrm{SO}_{4}$. Daily excretions of urine were measured using a graduated cylinder and feces with a digital balance in the morning between $6: 00 \mathrm{~h}$ and 7:00h. Of the daily feces voided by each heifer, after thorough mixing aliquots of about $50 \mathrm{~g}$ were sub-sampled for $\mathrm{N}$ estimation and put in separate pre-weighed screw-capped plastic bottles containing $50 \mathrm{ml}$ of $25 \%$ $\mathrm{H}_{2} \mathrm{SO}_{4}$. Of the daily urine voided by each heifer, after thorough mixing aliquots of about $50 \mathrm{ml}$ were sub-sampled for $\mathrm{N}$ estimation and put in separate pre-weighed screw-capped plastic bottles containing $150 \mathrm{ml}$ of $25 \% \mathrm{H}_{2} \mathrm{SO}_{4}$.

Of the total daily feces voided per heifer, and of green feed offered and refused, after thorough mixing about $100 \mathrm{~g}$ of each was subsampled and dried in an oven at $65^{\circ} \mathrm{C}$ daily. The aliquots taken daily from the dried samples were pooled over $7 \mathrm{~d}$ of the metabolism trial period and ground to pass through $1 \mathrm{~mm}$ sieve size and put in air tight plastic bags until chemically analyzed.

Digestibility coefficients of dry matter (DM), organic matter $(\mathrm{OM})$, crude protein $(\mathrm{CP})$, ether extract (EE), total carbohydrate (CHO), neutral detergent fiber (NDF), acid detergent fiber (ADF) and non-structural carbohydrates (NSC) and nitrogen (N) balance were calculated using data of nutrient intake and nutrients lost in feces:

$$
\begin{aligned}
& Y_{i}=\beta_{0}+\beta_{1} X+e_{i} \\
& \mathrm{~N} \text { balance }=\mathrm{N} \text { intake }-(\text { fecal } \mathrm{N}+\text { urinary } \mathrm{N})
\end{aligned}
$$

\section{Chemical analysis}

Samples of feed, residues and feces were analyzed for DM, $\mathrm{EE}, \mathrm{CP}$ and total ash ${ }^{10}$ and for NDF and ADF. ${ }^{11} \mathrm{OM}$ content was calculated by difference between absolute DM and ash. Total $\mathrm{N}$ in feed, feces, residues and urine was measured by Kjeldhal procedure using KELPLUS digester (Pelican-KES 12L R, India) and autodistiller (KELPLUS, CLASSIC DX). About $0.5 \mathrm{~g}$ of the dried feed and residue, $5 \mathrm{~g}$ of wet feces-acid mixture and $10 \mathrm{ml}$ of urine-acid mixture were taken for $\mathrm{N}$ estimations. For feed and residue samples, $\mathrm{N}$ was calculated as

$N(\%)=\frac{0.014 \times 0.01 \times \text { vol. } \mathrm{N} / 100 \mathrm{H}_{2} \mathrm{SO}_{4} \text { used for titration }(\mathrm{ml}) \times \text { vol. made }(\mathrm{ml})}{\text { Aliquot taken }(\mathrm{ml}) \times \text { sample weight } / \text { volume }(\mathrm{g}, \mathrm{ml})} x 100$

For feces and urine, same formula was used but corrections of sample weight and volume were made for the $\mathrm{H}_{2} \mathrm{SO}_{4}$ that was present in the samples for preservation purpose. Total $\mathrm{N}$ in urine was expressed as $\mathrm{mg} / 100 \mathrm{ml}(\mathrm{g} / \mathrm{l})$ instead of $\%$ and thus the numerator was multiplied by 1000 . The CP (\%) in feed, residue and feces was calculated by multiplying $\mathrm{N}$ content with the factor 6.25 . Total carbohydrate $(\mathrm{CHO})$ and non-structural $\mathrm{CHO}$ (NSC) contents were calculated as:

Total $\mathrm{CHO}(\% \mathrm{DM})=100-\mathrm{CP}(\% \mathrm{DM})-\mathrm{EE}(\% \mathrm{DM})-$ total ash (\%DM);

NSC $(\% \mathrm{DM})=$ Total $\mathrm{CHO}(\% \mathrm{DM})-$ ash-free NDF $(\% \mathrm{DM})$

\section{Statistical analyses}

Efficient (10 heifers) and less efficient (8 heifers) residual feed intake groups were identified and data collected on individual heifers were grouped for statistical analyses accordingly. The DM, water, CP, EE, NDF, ADF and TDN intakes; BW; BWG; digestibility DM, OM, $\mathrm{EE}, \mathrm{CP}, \mathrm{NDF}, \mathrm{ADF}$ and NSC in the diet; digestible DM, OM, EE, CP, $\mathrm{NDF}, \mathrm{ADF}, \mathrm{NSC}$ and TDN intakes and N-balance were calculated for individual heifers. Then Univariate ANOVA of the averages of the parameters measured on individual heifers was conducted using the GLM-general factorial procedure of SPSS for windows 10 .

The model used was model

$Y_{i}=\mu+X_{i}+e_{i}$

where $Y_{i}$ : Response variable; $\mu$ : Grand mean; $X_{i}$ : Treatment effect and $e_{i}$ : Random error

The interaction between water intake, DMI and volume of urine output were assessed using simple linear $\left(Y_{i}=\beta_{0}+\beta_{1} X+e_{i}\right)$ and 
multiple linear regressions $\left(Y_{i}=\beta_{0}+\beta_{1} X 1+\beta_{2} X 2+e_{i}\right)$; where $\mathrm{Y}_{\mathrm{i}}$ is dependent variable, $\beta_{0}=$ regression intercept, $\beta_{1}$ and $\beta_{2}$ are regression coefficients and $e_{i}$ is uncontrolled error.

\section{Results}

\section{Chemical composition}

The chemical composition of the green feed and concentrate fed to the heifers during the metabolism trial are presented in Table 1. Residues were collected for each heifer and analyzed separately and are not presented in this Table.

\section{Age and body size of the heifers}

Average body size parameters and age of the buffalo heifers that have been used in the trial after being separated into RFI-I (high RFI, +ve RFI, less efficient) and RFI-II (low RFI, -ve RFI, efficient) groups are presented in Table 2.

\section{Sorting out the heifers into RFI groups}

Those heifers with negative RFI-values were classified as having high-efficiency and those with positive RFI-values as low-efficiency.
ANOVA revealed that the RFI values of the two groups were significantly different $(\mathrm{p}<0.006$, Table 3$)$.

\section{Body sizes and nutrient intake}

The initial and final body weights of the buffalo heifers and their nutrient intakes during the $7 \mathrm{~d}$ metabolism trial are displayed in Table 4.

\section{Digestibility of nutrients}

Although differences were not statistically significant tendencies of higher nutrient digestibility coefficients were observed in the RFIII buffalo heifers (Table 5).

\section{Nitrogen balance ( $\mathbf{N})$}

As shown in Table 6, all heifers were on positive $\mathrm{N}$ balance; however RFI-II had higher $\mathrm{N}$ balance.

\section{Efficiency of water utilization}

The efficiency of utilization of water by the buffalo heifers is depicted in Table $7 \& 8$. Because the duration of the study was short (7d), the results should be taken as being more of informative than as final.

Table I Chemical composition of the green feed and concentrate fed to buffalo heifers during the metabolism trial

\begin{tabular}{llllllllll}
\hline \multirow{2}{*}{ Feed } & \multirow{2}{*}{ DM(\%) } & \multicolumn{6}{l}{ Nutrient(\%DM) } & & \\
\cline { 3 - 8 } & & Ash & OM & CP & EE & NDF & ADF & Total CHO & NSC \\
\hline Green feed* & 23.91 & 8.11 & 91.89 & 10.16 & 1.34 & 59.63 & 35.6 & 80.39 & 20.76 \\
Green feed** & 22.29 & 10.12 & 89.88 & 10.84 & 1.61 & 56.63 & 34.23 & 77.43 & 20.81 \\
Concentrate & 89.75 & 12.49 & 87.51 & 17.81 & 5.11 & 30.52 & 11.93 & 64.59 & 34.07 \\
\hline
\end{tabular}

DM, dry matter, OM, organic matter, CP, crude protein, EE, ether extract; NDF, neutral detergent fiber; ADF, acid detergent fiber; CHO, carbohydrate, NSC, non-structural $\mathrm{CHO}$

*first cycle; **second cycle

Table 2 The body size and age (mean \pm SE) of the buffalo heifers after being divided into RFI groups at the end of the $57 \mathrm{~d}$ of the feeding trial

\begin{tabular}{lllll}
\hline Parameters & RFI-I(Low) & RFI-II(High) & Grand mean & Sig.F \\
\hline Initial Body weight(kg) & $240 \pm 23$ & $236 \pm 20$ & $238 \pm 15$ & 0.91 \\
Final body weight(kg) & $278 \pm 23$ & $280 \pm 21$ & $279 \pm 16$ & 0.94 \\
Total body weight gain(kg) & $38.1 \pm 3.0$ & $44.0 \pm 2.7$ & $41.2 \pm 2.0$ & 0.15 \\
Body weight gain(g/head/d) & $669 \pm 52$ & $776 \pm 47$ & $722 \pm 35$ & 0.15 \\
Mid-test BW(kg) & $259 \pm 23$ & $259 \pm 20$ & $259 \pm 15$ & 0.98 \\
Mid-test BW $0.75(\mathrm{~kg})$ & $64.0 \pm 4.4$ & $64.3 \pm 4.0$ & $64 \pm 2.9$ & 0.96 \\
MBW $0.75(\mathrm{~kg})$ & $67.6 \pm 4.3$ & $68.4 \pm 3.9$ & $70.0 \pm 3.0$ & 0.89 \\
Age at start of data collection(d) & $630 \pm 48$ & $624 \pm 43$ & $627 \pm 32$ & 0.93 \\
Mid-test age(d) & $658 \pm 48$ & $652 \pm 43$ & $655 \pm 32$ & 0.93 \\
Feed conversion ratio(feed/BWG) & & & & \\
\hline
\end{tabular}

BW, body weight, MBW, metabolic body weight 
Table 3 Residual feed intake (RFI) of the buffalo heifers fed with green feed and concentrate for 57 days

\begin{tabular}{|c|c|c|c|c|c|c|c|c|c|c|}
\hline \multirow[b]{2}{*}{ Animal ID } & \multicolumn{10}{|c|}{ RFI-I(+ve RFI, low efficiency) } \\
\hline & 6351 & 6372 & 6385 & 6402 & 6422 & 6321 & 6336 & 6503 & & \\
\hline \multirow[t]{2}{*}{ RFI-value } & 0.688 & 0.06 & 0.01 & 0.035 & 0.043 & 0.14 & 0.011 & 0.121 & & \\
\hline & \multicolumn{10}{|c|}{ RFI-II(-ve RFI, high efficiency) } \\
\hline Animal ID & 6359 & 6382 & 6428 & 6348 & 6352 & 6358 & 6368 & 6380 & 6388 & 6476 \\
\hline RFI-value & -0.115 & -0.093 & -0.032 & -0.029 & -0.353 & -0.161 & -0.012 & -0.127 & -0.111 & -0.076 \\
\hline RFI-I & & \multicolumn{3}{|c|}{ RFI-II } & \multicolumn{2}{|c|}{ Grand mean } & $\mathbf{r}^{2}$ & \multicolumn{3}{|c|}{ Sig. F } \\
\hline $0.138 \pm 0.059^{a}$ & & & \multicolumn{2}{|c|}{$-0.1 \mathrm{II} \pm 0.053^{\mathrm{b}}$} & \multicolumn{2}{|c|}{$0.0138 \pm 0.04$} & 0.38 & & \multicolumn{2}{|l|}{0.006} \\
\hline
\end{tabular}

Row means with different superscript letters are significantly different at $p<0.05$

Table 4 Body sizes of heifers and their nutrient intakes (mean \pm SE) during metabolism trial

\begin{tabular}{|c|c|c|c|c|}
\hline Parameters & RFI-I(low efficiency) & RFI-II(high efficiency) & Grand mean & Sig. F \\
\hline Initial Body weight(kg) & $278 \pm 22$ & $284 \pm 20$ & $281 \pm 15$ & 0.82 \\
\hline Final body weight(kg) & $290 \pm 22$ & $296 \pm 20$ & $293 \pm 15$ & 0.85 \\
\hline DM intake(kg/head/d) & $8.20 \pm 0.80$ & $9.34 \pm 0.72$ & $8.77 \pm 0.54$ & 0.3 \\
\hline OM intake(kg/head/d) & $7.20 \pm 0.67$ & $8.68 \pm 0.60$ & $8.20 \pm 0.45$ & 0.3 \\
\hline $\mathrm{CP}$ intake(kg/head/d) & $1.22 \pm 0.09$ & $1.33 \pm 0.08$ & $1.28 \pm 0.06$ & 0.37 \\
\hline $\mathrm{EEI}(\mathrm{kg} / \mathrm{head} / \mathrm{d})$ & $0.24 \pm 0.02$ & $0.24 \pm 0.01$ & $0 . .24 \pm 0.01$ & 0.87 \\
\hline NDF intake(kg/head/d) & $3.99 \pm 0 . .37$ & $4.57 \pm 0.33$ & $4.28 \pm 0.25$ & 0.26 \\
\hline ADF intake(kg/head/d) & $2.20 \pm 0.21$ & $2.50 \pm 0.19$ & $2.35 \pm 0.14$ & 0.3 \\
\hline NSC intake(kg/head/d) & $2.33 \pm 0.19$ & $2.60 \pm 0.17$ & $2.46 \pm 0.13$ & 0.31 \\
\hline
\end{tabular}

DM, dry matter; OM, organic matter; CP, crude protein; EE, ether extract; NDF, neutral detergent fiber; ADF, acid detergent fiber; CHO, carbohydrate; NSC, non-structural $\mathrm{CHO}$

Table 5 Digestibility coefficient of nutrients $(\%$, mean \pm SE)) of the diet fed to the buffalo heifers

\begin{tabular}{|c|c|c|c|c|}
\hline Digestibility(\%) & RFI-I(low efficiency) & RFI-II(high efficiency) & Overall mean & Sig. F \\
\hline DM & $68.74 \pm 1.66$ & $70.87 \pm 1.48$ & $69.81 \pm 1.11$ & 0.351 \\
\hline OM & $71.49 \pm 1.72$ & $73.96 \pm 1.54$ & $72.73 \pm 1.15$ & 0.301 \\
\hline EED & $80.93 \pm 0.87$ & $81.68 \pm 0.77$ & $81.31 \pm 0.58$ & 0.53 \\
\hline NDF & $63.05 \pm 2.32$ & $66.33 \pm 2.08$ & $64.69 \pm 1.56$ & 0.307 \\
\hline ADF & $54.00 \pm 2.73$ & $59.60 \pm 2.44$ & $56.80 \pm 1.83$ & 0.146 \\
\hline NSC & $76.29 \pm 1.50$ & $78.69 \pm 1.34$ & $77.49 \pm 1.01$ & 0.252 \\
\hline
\end{tabular}

DM, dry matter; OM, organic matter; CP, crude protein; EE, ether extract; NDF, neutral detergent fiber; ADF, acid detergent fiber; CHO, carbohydrate; NSC, non-structural $\mathrm{CHO}$ 
Table 6 Nitrogen balance, crude protein retention and fat deposition (mean \pm SE) of Murrah buffalo heifers during the metabolism trial

\begin{tabular}{lllll}
\hline Parameters(g/head/d) & RFI-I(low efficiency) & RFI-II(high efficiency) & Overall mean & Sig. F \\
\hline Nitrogen intake & $184 \pm 13$ & $221 \pm 12$ & $202 \pm 9$ & 0.06 \\
Nitrogen excreted in feces & $120 \pm 5$ & $121 \pm 4$ & $121 \pm 3$ & 0.84 \\
Nitrogen excreted in urine & $36 \pm 5$ & $46 \pm 4$ & $41 \pm 3$ & 0.17 \\
Nitrogen balance & $38 \pm 9$ & $45 \pm 8$ & $42 \pm 6$ & 0.58 \\
\hline
\end{tabular}

Table 7 Water utilization efficiency of Murrah buffalo heifers fed green feed and concentrate and subjected to two times watering regimen (mean \pm SE) during the metabolism trial

\begin{tabular}{lllll}
\hline Parameters & RFI-I(low efficiency) & RFI-II(high efficiency) & Grand mean & Sig. F \\
\hline Water intake(I/head/d) & & & & \\
Drinking & $17.78 \pm 1.77$ & $20.23 \pm 1.58$ & $19.00 \pm 01.18$ & 0.32 \\
Absorbed(with feed) & $17.72 \pm 1.67$ & $19.66 \pm 1.40$ & $18.69 \pm 1.11$ & 0.4 \\
Total & $35.5 \pm 3.33$ & $39.5 \pm 2.98$ & $37.5 \pm 2.24$ & 0.38 \\
Water loss(I/head/d) & & & & 0.41 \\
Urine & $5.67 \pm 0.80$ & $6.58 \pm 0.72$ & $6.12 \pm 0.54$ & 0.4 \\
Feces & $11.92 \pm 0.70$ & $12.73 \pm 0.63$ & $12.33 \pm 0.47$ & 0.773 \\
Fecal water loss(\% WI) & $73.41 \pm 9.39$ & $69.70 \pm 8.40$ & $71.56 \pm 6.30$ & 0.638 \\
Fecal water loss(\% DMI) & $157 \pm 18$ & $145 \pm 16$ & $151 \pm 12$ & 0.794 \\
Urine volume(\% WI) & $31.84 \pm 2.28$ & $32.65 \pm 2.04$ & $32.25 \pm 1.53$ & 0.652 \\
\hline Urine volume(\% DMI) & $69.09 \pm 10.42$ & $75.51 \pm 9.32$ & $72.30 \pm 6.99$ & \\
\hline
\end{tabular}

WI, water intake; DMI, dry matter intake

Table 8 Results of linear regression analyses on water intake (l/head/d), DMI (kg/head/d) and urine output (l/head/d); and multiple linear regression analyses of urine output on water intake (WI) and DMI

\begin{tabular}{|c|c|c|c|c|c|c|c|c|}
\hline \multirow{2}{*}{ Dependent variable } & \multicolumn{2}{|c|}{ Independent variables } & \multirow{2}{*}{$\beta \mathbf{I}$} & \multirow{2}{*}{$\beta 2$} & \multirow{2}{*}{ Intercept } & \multirow{2}{*}{$\mathbf{R}^{2}$} & \multirow{2}{*}{ SE } & \multirow{2}{*}{ sig. $F$} \\
\hline & $\mathbf{X I}$ & $\times 2$ & & & & & & \\
\hline Urine Output & WI & & 0.269 & & 1.204 & 0.4 & 1.99 & 0 \\
\hline Water intake(WI) & DMI & & 0.915 & & 10.42 & 0.19 & 5.44 & 0 \\
\hline DM intake(DMI) & WI & & 0.204 & & 5.34 & 0.19 & 2.57 & 0 \\
\hline Urine output & DMI & & 0.561 & & 1.112 & 0.39 & 2.01 & 0 \\
\hline Urine output & WI & DMI & 0.19 & 0.387 & -0.865 & 0.55 & 1.73 & 0 \\
\hline
\end{tabular}




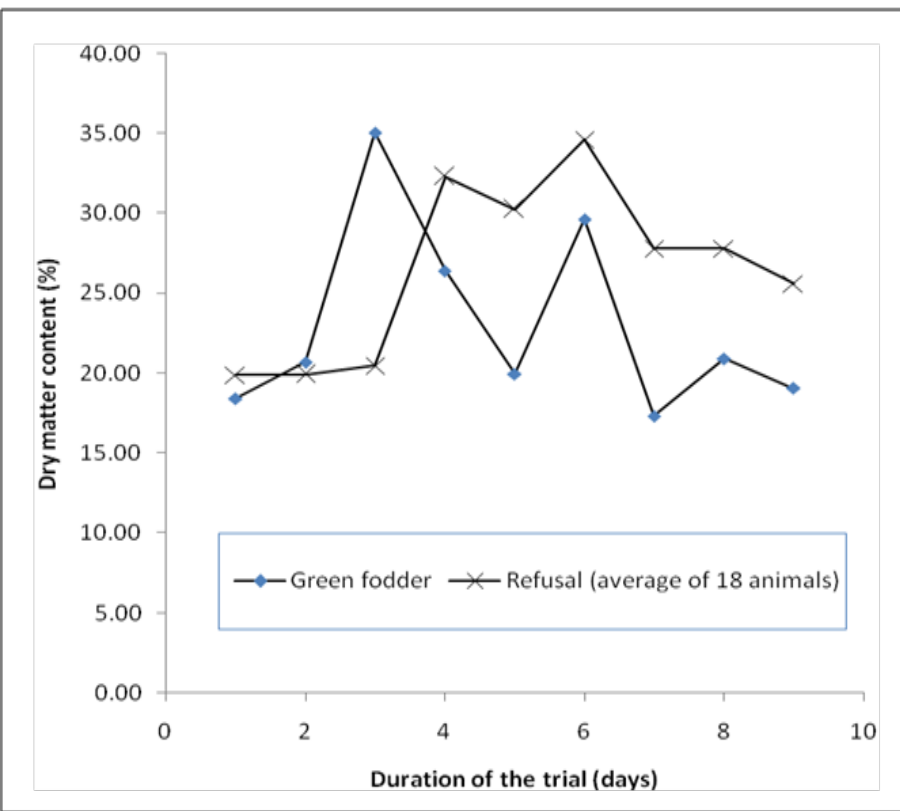

Figure I Dry matter content of the green feed and residue during the metabolism trial.

\section{Discussion}

\section{Chemical composition}

The DM content of the green feed was higher during the metabolism trial than during feeding trial because the plant materials were at the later stage of maturity and the heifers were selecting the leaves, the nutritious part of the forage, and thus the DM content of the refusal was much higher than the offer (Figure 1). The CP and NDF contents of the green feed were almost similar during the feeding and metabolism trials, but Total CHO and NSC were less, and EE and ash more during the feeding than the metabolism trial (18).

\section{Sorting out the heifers into RFI groups}

The general trend observed was that heifers under RFI-II (efficient) excelled in most of the parameters, although statistical differences were noted in very few cases. The $\mathrm{R}^{2}$ values were extremely low possibly because of small sample size and perhaps due to lowered precision in feed intake measurements caused by extreme variation in DM content of the green feed. It was also not possible to run post hoch because df was 1 as there were only two RFI groups. As opposed to this study, most RFI studies are done with large number of animals, over longer periods of time where feed intakes are also measured by auto-feeders [examples: 1.3million cattle (4); 148 steers (5); 98 steers (6)] which minimize experimental errors. Testing period of 63-90days for estimating RFI was reported as also being too short (9) and 112days is recommended (2). They have also reflected that testing young animals may not reflect the overall RFI particularly in circumstances where large seasonal effects or different diets come into play. It is important to realize that RFI value of a given livestock is not as such a fixed value, and could vary depending upon models used and precision of data collection. Supporting evidence have been reported earlier ${ }^{12}$ where more than half steers tested changed their RFI estimate by more than 0.5 standard deviations or $0.20 \mathrm{~kg} \mathrm{DM} / \mathrm{d}$ when measured on grower and finisher diets sequentially.

\section{Body sizes and nutrient intake}

Because of the stress the animals were subjected to in the cages and the short duration, the BWG here during the metabolism trial may not necessarily represent the growth performance of the heifers. At the end of the metabolism trial RFI-II heifers consumed more nutrient but attained similar body weight gain compared to RFI-I heifers, which is different from the trend observed during the feeding trial.

\section{Digestibility of nutrients}

The higher OM, CP and NSC intakes by the RFI-II group could have contributed to the observed improvement in the digestibility coefficients. The lower DM, OM and CP digestibility in RFI-I as compared to RFI-II heifers could be due to the relatively lower OM and CP intakes of RFI-I. As a result fiber degradation was lower in RFI-I than RFI-II heifers. Similar trend has been explained as being caused by differences in microbial growth and fermentation in the rumen of sheep. ${ }^{13}$

\section{Nitrogen balance $(\mathbf{N})$}

As shown in Table 6, all heifers were on positive $\mathrm{N}$ balance; however RFI-II had higher $\mathrm{N}$ balance. The biological value of $\mathrm{N}(\mathrm{N}$ balance/Digestible $\left.\mathrm{N}^{*} 100\right)$ was also higher in RFI-II heifers because larger percentage (55\% vs. $44 \%$ ) of the total $\mathrm{N}$ absorbed from the gut was retained in the body. On average only about $16 \%$ of the $\mathrm{N}$ consumed was retained (15\% by RFI-I and $18 \%$ by RFI-II). Of the total $\mathrm{N}$ excreted, most of it was in feces $(75 \%)$ and a small fraction in urine (25\%). RFI-I heifers lost more of the $\mathrm{N}$ intake in feces $(64$ vs. $61 \%$ ) than the heifers in RFI-II but they both lost about same amount in urine $(21 \%)$, which indicates that RFI-I heifers were less efficient in digesting and metabolizing $\mathrm{N}$ than RFI-II heifers, i.e. $\mathrm{N}$ was poorly digested, and of the lesser $\mathrm{N}$ absorbed same level was metabolized. The differences in $\mathrm{N}$ utilization is mainly related to differences in digestibility of protein, which implies that the lower efficiency of utilization of RFI-I heifers were mainly because of lower $\mathrm{N}$ digestibility.

\section{Efficiency of water utilization}

The heifers with similar genetic background and physiological response to their environment, without forgetting individual differences, they might have had similar evaporative water loss per unit of body weight. Taking into account that evaporative water loss in the genotype is constant, the differences between water intake (drinking + adsorbed) and water loss (feces + urine) calculated for these heifers could reflect their differences in water use efficiency. ${ }^{14-17}$

Relatively similar amounts of drinking and adsorbed water were consumed and tremendous amount of water was contributed by the green feed. Fecal and urinary water losses were more closely associated with DMI than with water intake. As can be seen in Table 7 , in both fecal and urinary water losses, the influence of DMI was about twice as much as that of water intake. However, it can be seen that urine output is a combined/multiple effect of DMI and water consumption (Table 8), and is affected more by the combined effect than by water and DM intakes separately; i.e., animals consuming more water and feed, excrete more urine than animals consuming less of both. ${ }^{18,19}$ Earlier report indicated water intake to vary from 6.7 to $11.5 \mathrm{l} / \mathrm{d}$ in Nili Ravi buffalo heifers (8month old and $120 \mathrm{~kg} \mathrm{BW})$ depending up on different feeds. ${ }^{7}$ This level of water intake is small as compared to the results obtained for the buffalo heifers in the current study. ${ }^{20,21}$ 


\section{Conclusion}

This metabolism trial was conducted for $7 \mathrm{~d}$ following a $57 \mathrm{~d}$ feeding trial with 18 Murrah buffalo heifers $(238 \pm 63 \mathrm{~kg}$; $627 \pm 131$ days old) and metabolism of nutrients recorded. The heifers were already grouped into high (RFI-II) and low (RFI-II) feed efficiency groups at the end of the feeding trial by regressing DMI $(\mathrm{g} / \mathrm{head} / \mathrm{d})$ on BWG $(\mathrm{g} / \mathrm{head} / \mathrm{d})$ and mid-test MBW $(\mathrm{kg})$. Although differences were not statistically significant, RFI-II heifers had higher DM and nutrient intakes and digestibility of nutrients over RFI-I heifers, because RFIII had higher DMD $(68.74 \pm 1.66$ vs $70.84 \pm 1.48 \%)$, OMD (71.49 \pm 1.72 vs $73.96 \pm 1.54 \%)$, CPD $(89.89 \pm 0.61$ vs $90.60 \pm 0.55 \%)$ and NDFD $(63.05 \pm 2.32$ vs $66.33 \pm 2.08 \%)$; and better metabolism of energy and protein.

Of the total water intake, RFI-II heifers excreted less percentage of it in feces $(73.41 \pm 9.39$ vs $69.70 \pm 8.40 \%$ of water intake, for RFI-I and RFI-II, respectively) to improve the availability of water for metabolism; and that which was excreted in urine was reversed ( $31.84 \pm 2.28$ vs $32.65 \pm 2.04 \%$, for RFI-I and RFI-II, respectively). When fecal and urinary water losses were expressed as\% of DMI the same trend was noted (fecal water loss: $157 \pm 18$ vs $145 \pm 16 \%$ DMI; urinary water loss: $69 \pm 10$ vs $76 \pm 9 \%$ DMI, for RFI-I and RFI-II, Respectively).

This trial has shown that selecting against RFI has the potential to further sort out feed and water efficiency in young growing buffalo heifers and could help as the preliminary step in early identification of feed and water efficient heifers without compromising productivity later with mature cows; however, the question at what stage of production in dairy animals should animals be tested for RFI is a big challenge and thus if these potential categorization of efficiency will be expressed or maintained when the heifers come into lactation has to be researched.

\section{Acknowledgements}

Authors acknowledge Dairy Cattle Nutrition Division of National Dairy Research Institute of India, Department of Science \& Technology, Govt. of India, CV Raman Fellowship for African Researcher, Federation of Indian Chamber of Commerce and Industry (FICCI) for funding and facilitating the research work.

\section{Conflict of interest}

Author declares that there is no conflict of interest.

\section{References}

1. Arthur PF, Archer JA, Johnston DJ, et al. Genetic and phenotypic variance and covariance components for feed intake, feed efficiency and other post weaning traits in Angus cattle. J Anim Sci. 2001;79(11):2805-2811.

2. Ferrell CL, Jenkins TG. Cow type and the nutritional environment: Nutritional aspects. J Anim Sci. 1985;61(3):725-741.

3. Montano-Bermudez M, Nielsen MK, Deutscher GH. Energy requirements for maintenance of crossbred beef cattle with different genetic potential for milk. J Anim Sci. 1990;68(8):2279-2288.
4. Gibb DJ, McAllister TA. The impact of feed intake and feeding behavior of cattle on feedlot and feed bunk management. Alberta; 19991:1-20.

5. NRC Nutrient Requirements of beef Cattle. 7th ed. USA: National Academy Press; 2000.

6. Koch RM, Swiger LA, Chambers D, et al. Efficiency of feed use in beef cattle. Journal Animal Science. 1963;22(2):486-494.

7. Herd RM, Bishop SC. Genetic variation in residual feed intake and its association with other production traits in British Hereford cattle. Livestock Prod Sci. 2000;63:111-119.

8. D. Korver, J Morrison, editor. Proc. 20th Western Nutr. Conference.

9. Archer JA, Pitchford WS, Hughes TE, et al. Genetic and phenotypic relationships between food intake, growth, efficiency and body composition of mice post weaning and at maturity. Animal Science. 1998;67(1):171-182.

10. AOAC, Association of Official Analytical Chemists. Official method of analysis of AOAC International. 18th ed. USA; 2005.

11. Negesse T, Datt C, Kundu SS. Variability in residual feed intake and nutrient utilization in Murrah buffalo heifers. Trop Anim Health Prod. 2016;48(8):1577-1584.

12. Durunna ON, Mujibi FDN, Goonewardene L, et al. Feed efficiency differences and reranking in beef steers fed grower and finisher diets. $J$ Anim Sci. 2011;89(1):158-167.

13. Bonsi MLK, Tuah AK, Osuji PO, et al. The effect of protein supplement sources or supply pattern on the intake, digestibility, rumen kinetics, nitrogen utilization and growth of Ethiopian Menze sheep fed teff straw. Animal Feed Science Technol. 1996;64:11-25.

14. Arthurb PF, Herd RM. Efficiency of feed utilization by livestock Implications and benefits of genetic improvement. Canadian Journal Animal Science. 2005;85(3):281-290.

15. Basarab JA, Price MA, Aalhus JL, et al. Residual feed intake and body composition in young growing cattle. Canadian Journal Animal Science. 2003;83(2):189-204.

16. Basarab JA. Feed Efficiency in Beef Cattle: RFI and its Economic Benefits. Calgary, Alberta: 16th World Hereford Conference, 2012.

17. Bhatti JA, Younas M, Abdullah M, et al. Feed intake, weight gain and haematology in Nili-Ravi buffalo heifers fed on mott grass and berseem fodder substituted with saltbush (Atriplex amnicola). Pak Vet J. 2009;29(3):133-137.

18. NRC, Nutrient Requirements for dairy Cattle. 7th ed. USA: National Academy Press; 2001.

19. Salmon RK, Bailey DRC, Weingardt R, et al. Growth efficiency in mice selected for increased body weight. Can J Anim Sci. 1990;70:371-81.

20. Van Soest PJ, Robertson JB, Lewis BA. Method for dietary fiber, neutral detergent fiber and non starch polysaccharides in relation to animal nutrition. Journal Dairy Science. 1991;74(10):3583-3597.

21. Wang Z, Basarab JA, Goonewardene LA, et al. Test duration for residual feed intake in commercial Bulls. Journal of Animal and Veterinary Advances. 2005;84(9):2289-2298. 